\title{
Blood Flow and Oxygen Delivery to the Organs of the Neonatal Lamb as a Function of Hematocrit
}

\author{
IAN R. HOLZMAN, BRIAN TABATA, AND DANIEL I. EDELSTONE \\ University of Pittsburgh, School of Medicine, Magee-Womens Hospital, Pittsburgh, Pennsylvania 15213
}

\begin{abstract}
We chronically catheterized 15 newborn lambs $(9.5 \pm 2.8$ days) and measured the distribution of cardiac output by the radionuclide-microsphere technique at hematocrits ranging from 10 volumes \% to 55 volumes $\%$. Seven animals were made progressively anemic and eight polycythemic by means of exchange transfusions. Cardiac output and heart rate increased with decreasing hematocrit while whole body oxygen consumption showed a small decrease during severe anemia. Both cerebral and cardiac blood flow markedly increased during anemia which assured a relatively stable oxygen delivery to both organs. The changes seen for blood flow to the carcass (skin, bones, and muscle) were predictable from the effects of blood viscosity: small decreases in flow at the highest hematocrits and small increases in flow at the lowest hematocrits. Consequently, oxygen delivery was as low as $1 \mathrm{ml}$ of oxygen/min/100 $\mathrm{g}$ at a hematocrit of 10 volumes $\%$. Renal blood flow remained unchanged while oxygen delivery fell when hematocrit was decreased. Hepatic oxygenation was measured using a modification of the Fick principle. Hepatic blood flow showed only a small decrease as hematocrit increased and changed minimally during anemia resulting in a falling delivery of oxygen with anemia. A stable hepatic oxygen consumption was assured by a marked increase in oxygen extraction during anemia. Two differing organ responses to changes in hematocrit can be seen in the newborn: the brain and heart vary blood flow to assure an adequate delivery of oxygen while a number of other organs show less blood flow regulation and, most likely, vary oxygen removal from blood. Over a wide range of hematocrits, compensatory responses occur in the newborn which effectively prevent the development of tissue hypoxia. (Pediatr Res 20: 1274-1279, 1986)
\end{abstract}

The physiologic responses that occur with isovolemic anemia and polycythemia reflect the continual interplay between the requirements for tissue oxygenation and the rheologic effects of changes in blood viscosity. While information is available concerning the changes in the distribution of cardiac output for both the fetus (1) and adults (2-8) with anemia and polycythemia, there are little data for the newborn. Two patterns of organ blood flow response can be seen in conditions of decreased oxygen availability: the brain, heart and adrenal glands meet their oxygen requirements by increasing organ blood flows; the majority of other organs regulate the extraction of oxygen by varying capil-

Received December 3, 1985; accepted July 22, 1986.

Ian R. Holzman, M.D., Magee-Womens Hospital, Department of Pediatrics, Division of Neonatology, Forbes Avenue and Halket Street, Pittsburgh, PA 15213.

Supported in part by the National Institute of Child Health and Human Development (Grant HD16368) and the Cradle Roll Auxiliary of Magee-Womens Hospital. lary density and the oxygen diffusion gradient. When both oxygen content and blood viscosity are changing, complex physiologic adjustments are clinically important for the maintenance of a stable oxygen delivery to the organs of the newborn. Both anemia and polycythemia can occur from a variety of causes related to chronic and acute events during pregnancy and delivery. Understanding the limits within which adequate tissue oxygenation occurs offers both prognostic and therapeutic possibilities in the care of infants, especially as we try to determinate the optimal hematocrit for sick newborns.

The purpose of the present experiments was to investigate the changes in organ blood flow and oxygen delivery in healthy newborn lambs made acutely anemic or polycythemic. The particular methodology employed in this experimental model afforded us the opportunity to obtain an approximation of hepatic oxygen consumption without additional instrumentation. Because the liver must obtain a significant portion of its oxygen delivery from portal venous blood, the mechanisms available to assure adequate tissue oxygenation assume added importance. Hepatic hypoxia has been suggested as one possible etiologic factor in the hypoglycemia seen in polycythemic infants (9). Disturbances in hepatic oxygenation may also contribute to the hyperbilirubinemia seen in a number of neonatal conditions involving circulatory disturbances. It is for these reasons that we have chosen to present the additional data on the oxygen consumption of a single organ, the liver. Hematocrit changes were performed by isovolemic exchange transfusions through chronically implanted indwelling catheters in order to eliminate the effects of hyper- or hypovolemia.

\section{METHODS}

Animal preparation. We anesthetized 15 lambs, 2-10 days of age with $10 \mathrm{ml} / \mathrm{kg}$ of intramuscular ketamine (Ketalar, ParkeDavis) with supplemental doses as required. In each lamb we surgically implanted two polyvinyl catheters into the abdominal aorta via the hind limb arteries; two catheters into the inferior vena cava with one advanced above the diaphragm and the other mid-abdominally, both via hind limb veins; a catheter into the portal sinus via the umbilical vein; and catheters into the left and right ventricles; via the left common carotid artery and external jugular vein, respectively. All catheters were filled with $0.9 \%$ saline solution containing heparin $(100 \mu / \mathrm{ml})$, tunneled subcutaneously to the flank and externalized into a pouch. Postoperative recovery ranged from 3-8 days during which the lambs were fed ad libitum by their mothers. The animals were taken daily to the laboratory for conditioning and the catheters were flushed with a saline and heparin solution. Benzathine penicillin and streptomycin antibiotic prophylaxis were given for the first 3 postoperative days.

Experimentation protocol. Each lamb was placed into a large wood and plexiglass box and fasted for $3 \mathrm{~h}$. The ambient temperature was kept at $\sim 21^{\circ} \mathrm{C}$. We then performed three to five 
measurements of organ blood flow, oxygen delivery, total body and hepatic oxygen consumption, and extraction at various hematocrit levels over 4-6h. A Beckman R-611 recorder continuously measured systemic arterial and portal venous pressures, using Statham P23Db pressure transducers, and heart rate by cardiotachometer. After determining the hematocrit by the microcapillary centrifugation technique, we simultaneously withdrew blood samples from the arterial and portal venous catheters for the analyses of $\mathrm{pH}, \mathrm{PO}_{2}$, and $\mathrm{PCO}_{2}$ (blood gas meter, Instrument Laboratories) and oxygen content (Lex- $\mathrm{O}_{2}-\mathrm{Con}$, Lexington Instruments). An oxygen content analysis was also made on blood samples from the right ventricle. Immediately after sampling we injected $2-5 \times 10^{5}$, radionuclide labeled $\left(\mathrm{Ce}^{141}, \mathrm{Cr}^{51}\right.$, $\left.\mathrm{I}^{125}, \mathrm{Nb}^{95}, \mathrm{Sc}^{46}, \mathrm{Sr}^{85}\right), 15-\mu$ diameter microspheres into the left ventricle while withdrawing a reference blood sample from the femoral artery catheter at $3.7 \mathrm{ml} / \mathrm{min}$ for $90 \mathrm{~s}$, using a Harvard pump. For hematocrits less than $15 \%, 7.5 \mathrm{ml} / \mathrm{min}$ withdrawal rate was used (10). Total blood volume removed for blood sampling and microsphere withdrawal per experiment averaged $13 \mathrm{ml}$, which was replaced by the subsequent exchange transfusion. To vary the hematocrit, we performed exchange transfusions (simultaneous infusion and withdrawal through the venous and arterial catheters, respectively) over $10 \mathrm{~min}$ and waited 40 $60 \mathrm{~min}$ for stabilization and equilibration before repeating the measurements. The first seven lambs were made progressively anemic (lowest hematocrit $=10 \%$ ) by receiving newborn lamb plasma and/or maternal plasma (diluted $15 \%$ by volume with $0.9 \%$ saline solution to give comparable total protein concentrations). We made the remaining eight lambs polycythemic (highest hematocrit $=54.5 \%$ ) by infusing lamb red blood cells when available or a 50\%:50\% mixture of maternal and fetal red blood cells.

Tissue handling and data calculation. All lambs were killed with an overdose of pentobarbital sodium. Each lamb was autopsied in order to confirm the positions of the catheters. All organs and the carcass were incinerated at $280^{\circ} \mathrm{C}$ for $72 \mathrm{~h}$ after which the ashed tissues were packed into counting vials (11). The amounts of each radionuclide in the organs, carcass, and reference arterial blood samples were measured with a $\gamma$ scintillation counter (model 1185R Searle Analytic) and a multichannel pulse-height analyzer (Ultima II, Norland). Nuclide isotopes were separated and blood flows were calculated by computer (Nova III, Data General; average error in calculation of corrected counts/minute for each isotope was less than 5\%)(12). Reference arterial blood samples contained more than 1500 microspheres to ensure that the error in any blood flow measurement was less than $5 \%$ at the $95 \%$ confidence limits (13).

Calculations. Blood flow and cardiac output were calculated with the reference sample blood flow technique (11):

$$
\text { Organ blood flow }\left(\dot{\mathrm{Q}}_{\text {organ }}\right)=\left(\mathrm{cpm}_{\text {organ }} / \mathrm{cpm}_{\text {ref }}\right) \dot{\mathrm{Q}}_{\text {ref }}
$$

where cpm is the radioactive counts/min in an organ or reference arterial blood flow sample and $\dot{Q}_{\text {ref }}$ is the reference arterial blood flow as determined by calibration of the withdrawal pump. Cardiac output was the sum of the individual organ blood flows. Liver blood flow $\left(\dot{Q}_{\mathrm{L}}\right)$ was calculated using the relationship

$$
\dot{\mathrm{Q}}_{\mathrm{L}}=\dot{\mathrm{Q}}_{\mathrm{HA}}+\dot{\mathrm{Q}}_{\mathrm{PV}}=\dot{\mathrm{Q}}_{\mathrm{HV}}
$$

where $\dot{\mathrm{Q}}_{\mathrm{HA}}$ was hepatic arterial blood flow, $\dot{\mathrm{Q}}_{\mathrm{PV}}$ was portal venous blood flow, and $\mathrm{Q}_{\mathrm{HV}}$ was hepatic venous blood flow. Since the only microspheres reaching the liver (L) were those distributed by the hepatic artery, then:

$$
\dot{\mathrm{Q}}_{\mathrm{HA}}=\left(\mathrm{cpm}_{\mathrm{L}} / \mathrm{cpm}_{\mathrm{ref}}\right) \dot{\mathrm{Q}}_{\mathrm{ref}}
$$

and $\dot{Q}_{\mathrm{PV}}$ was the sum of the arterial blood flows to the organs drained by the portal system

$$
\begin{aligned}
& \dot{\mathrm{Q}}_{\mathrm{pV}}=\dot{\mathrm{Q}}_{\mathrm{GI}}+\dot{\mathrm{Q}}_{\text {spleen }}+\dot{\mathrm{Q}}_{\text {pancreas }}+\dot{\mathrm{Q}}_{\text {mesenteries }} \\
= & \dot{\mathrm{Q}}_{\mathrm{Gl}}+\left(\frac{\mathrm{cpm}_{\text {spleen }}+\text { pancreas }+ \text { mesenteries }}{\mathrm{cpm}_{\mathrm{ref}}}\right) \dot{\mathrm{Q}}_{\mathrm{ref}}
\end{aligned}
$$

where $\dot{\mathrm{Q}}_{\mathrm{GI}}$ was the sum of the blood flows to the stomach, small intestine, and colon.

Hepatic oxygen consumption $\left(\dot{\mathrm{V}}_{\mathrm{L}} \mathrm{O}_{2}\right)$ was calculated using a modification of the Fick principle:

$$
\dot{\mathrm{V}}_{\mathrm{L}} \mathrm{O}_{2}=\mathrm{D}_{\mathrm{L}} \mathrm{O}_{2}-\dot{\mathrm{Q}}_{\mathrm{HV}} \cdot \mathrm{C}_{\mathrm{HV}} \mathrm{O}_{2}
$$

where $\dot{\mathrm{V}}_{\mathrm{L}} \mathrm{O}_{2}$ was the oxygen consumption of the liver, $\mathrm{D}_{\mathrm{L}} \mathrm{O}_{2}$ was the total quantity of oxygen delivered to the liver via the portal vein $\left(\dot{\mathrm{Q}}_{\mathrm{PV}} \cdot \mathrm{C}_{\mathrm{PV}} \mathrm{O}_{2}\right)$ and the hepatic artery $\left(\dot{\mathrm{Q}}_{\mathrm{HA}} \cdot \mathrm{C}_{\mathrm{HA}} \mathrm{O}_{2}\right)$ and $\mathrm{C}_{\mathrm{HV}} \mathrm{O}_{2}$ was the oxygen content in hepatic venous blood. Although we measured hepatic arterial and portal venous flows and oxygen contents, the difficulty of obtaining a well-mixed hepatic venous blood sample in an unanesthetized animal precluded direct measurement of $\mathrm{C}_{\mathrm{HV}} \mathrm{O}_{2}$ (14). Nevertheless, we could calculate $\mathrm{C}_{\mathrm{HV}} \mathrm{O}_{2}$ because

$$
\dot{\mathrm{Q}}_{\mathrm{HV}} \cdot \mathrm{C}_{\mathrm{HV}} \mathrm{O}_{2}=\dot{\mathrm{Q}}_{\mathrm{IVC}} \cdot \mathrm{C}_{\mathrm{IVC}_{\mathrm{t}}} \mathrm{O}_{2}-\dot{\mathrm{Q}}_{\mathrm{IVC}_{\mathrm{a}}} \cdot \mathrm{C}_{\mathrm{IVC}} \mathrm{O}_{2}
$$

where $\dot{\mathrm{Q}}_{I V C_{t}}$ was the blood flow in the thoracic portion of the inferior vena cava (equivalent to arterial blood flows to all structures below the diaphragm), $\mathrm{C}_{\mathrm{IVC}_{\mathrm{t}}} \mathrm{O}_{2}$ was the oxygen content of blood in, the thoracic portion of the inferior vena cava, $\dot{\mathrm{Q}}_{\mathrm{IVC}_{\mathrm{a}}}$ was the blood flow in the abdominal portion of the inferior vena cava (equivalent to arterial flow to all structures below the diaphragm excluding $\dot{\mathrm{Q}}_{\mathrm{L}}$ ) and $\mathrm{C}_{\mathrm{IVC}_{\mathrm{a}}} \mathrm{O}_{2}$ was the oxygen content of blood in the abdominal portion of the inferior vena cava. All the terms in the right-hand portion of the equation were measured [a detailed validation of this method is given by Edelstone and Holzman (13)].

Whole body $\mathrm{O}_{2}$ uptake = (cardiac output) $\left(\mathrm{C}_{\mathrm{A}} \mathrm{O}_{2}-\mathrm{C}_{\mathrm{RV}} \mathrm{O}_{2}\right)$ where $\mathrm{C}_{\mathrm{a}} \mathrm{O}_{2}$ and $\mathrm{C}_{\mathrm{RV}} \mathrm{O}_{2}$ were the oxygen concentration in aortic and right ventricular blood, respectively.

Blood flow and oxygenation data for the gastrointestinal tract in this series of animals have been previously published (15).

Data analysis. Arterial oxygen contents, organ blood flows, organ oxygen deliveries, as well as hepatic oxygen consumption $\left(\dot{\mathrm{V}}_{\mathrm{L}} \mathrm{O}_{2}\right)$ and hepatic oxygen extraction $\left(\dot{\mathrm{V}}_{\mathrm{L}} \mathrm{O}_{2} / \mathrm{D}_{\mathrm{L}} \mathrm{O}_{2}\right)$ and cardiac output were plotted against hematocrit. We defined the mathematical relationships between independent and dependent variables using the least squares method based on covariance analysis (16). The advantage of this statistical method is that it takes into account the individual responses of the animals. A probability of $p<0.05$ (two tailed) was judged to be statistically significant.

\section{RESULTS}

We performed 59 experiments on 15 newborn lambs. Nine lambs had four consecutive measurements obtained, while three lambs had five measurements and three lambs had three measurements. There were no statistical differences between those lambs made anemic and those made polycythemic as far as their mean day of study $(9.5 \pm 2.8$ days, mean $\pm \mathrm{SD})$, weight at the time of study $(4.65 \pm 1.24 \mathrm{~kg})$, or initial hematocrit $(27.7 \pm 7.6$ vol\%). Similarly, the two sets of lambs were comparable at the beginning of the study for mean arterial blood pressure $(67.5 \pm$ $10.4 \mathrm{~mm} \mathrm{Hg})$, blood oxygen contents $(11.7 \pm 3.9 \mathrm{vol} \%)$, and total body oxygen consumption $(15.8 \pm 4.0 \mathrm{ml} / \mathrm{min} / \mathrm{kg})$. At no time during the study was there any significant change in blood gases or $\mathrm{pH}$.

Figure $1 a$ illustrates the changes in cardiac output which occurred with changing hematocrit $(\mathrm{y}=707-126.5 \mathrm{Lnx}, r=$ $-0.69, p<0.001$ ). A similar curve was obtained if heart rate was plotted against hematocrit. Figure $1 b$ demonstrates the relationship between whole animal oxygen consumption and hematocrit. There was a statistically significant relationship such that oxygen consumption decreased at lower hematocrits $(y=28.7-$ $\left.22\left(\frac{\operatorname{Lnx}}{\sqrt{\mathrm{x}}}\right), r=-0.32, p<0.05\right)$. 

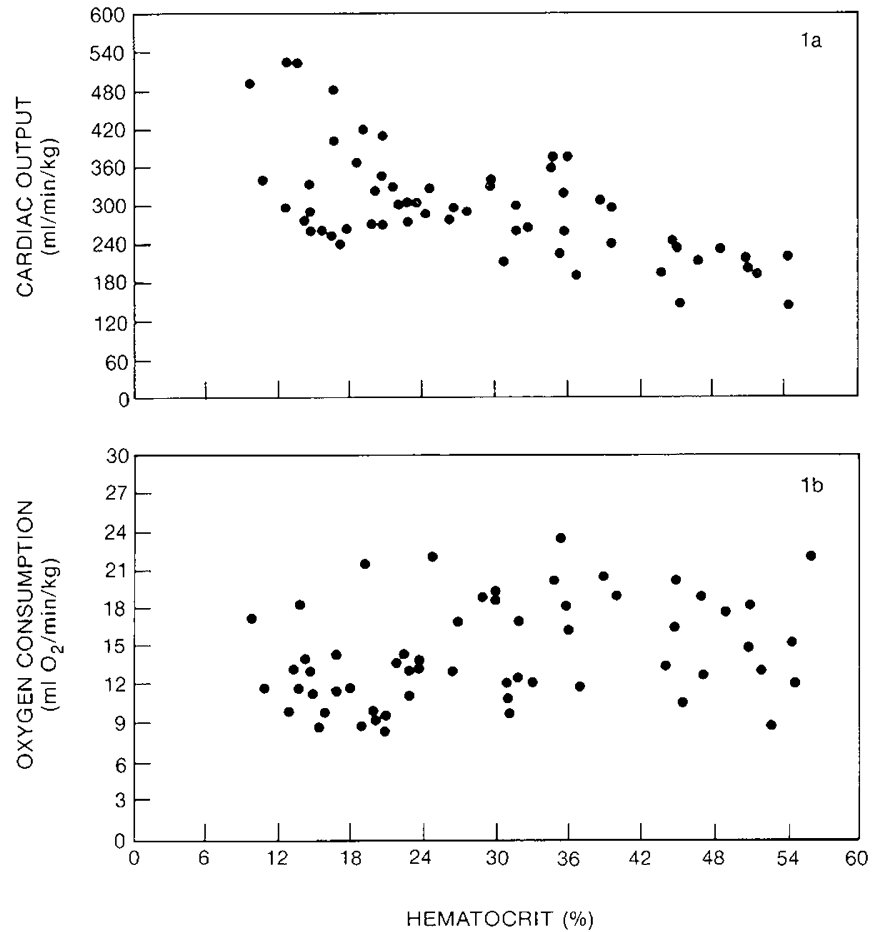

Fig. 1. $a$, the continuous relationship between cardiac output and changes in hematocrit; $n=59$ points from 15 lambs. $b$, the relationship between whole animal oxygen consumption and hematocrit. There is a statistically significant decrease in oxygen consumption at lower hematocrits; $n=59$ points from 15 lambs.
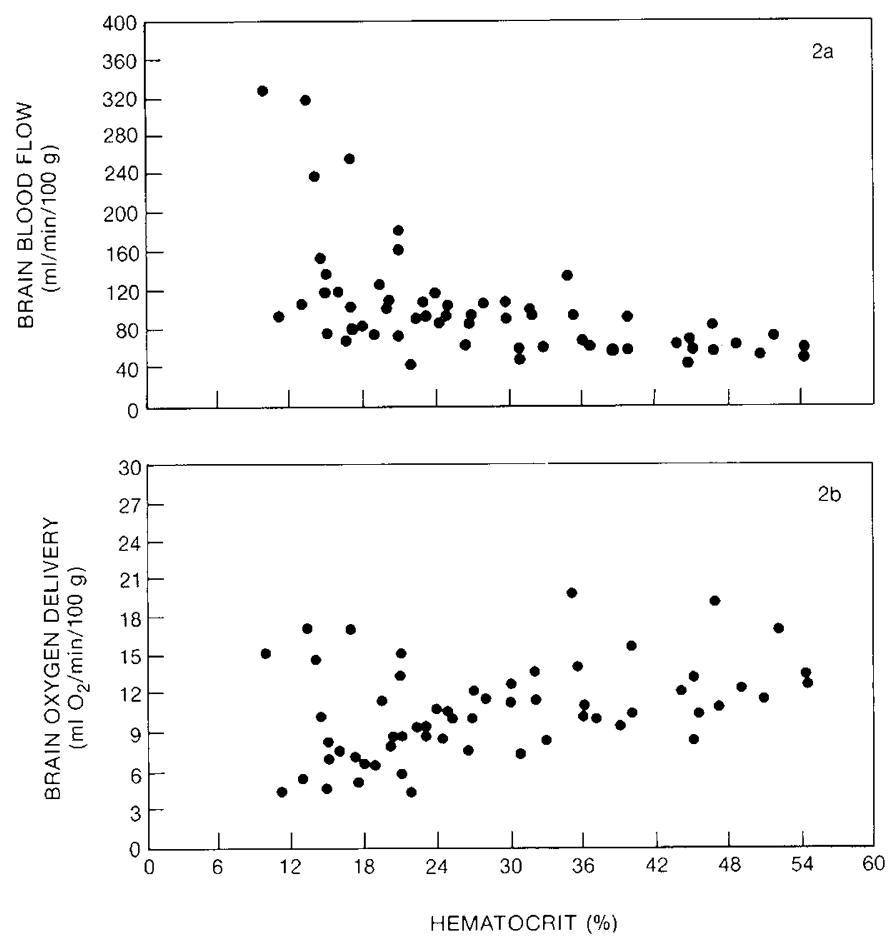

Fig. 2. $a$, the relationship between cerebral blood flow and changes in hematocrit; $n=59$ points from 15 lambs. $b$, the relationship between cerebral oxygen delivery and changes in hematocrit; $n=59$ points from 15 lambs.

The striking increase in cerebral blood flow at decreased hematocrits is shown in Figure $2 a$. Although the four highest points occurred in two lambs, all of the lambs made anemic showed a consistent increase in blood flow as hematocrit was decreased (y $\left.=57.8+\frac{20036}{\mathrm{x}^{2}}, r=-0.68, p<0.001\right)$. In the most extreme case, blood flow increased from $89 \mathrm{ml} / \mathrm{min} / 100 \mathrm{~g}$ of brain at a hematocrit of 30 volumes $\%$ to $329 \mathrm{ml} / \mathrm{min} / 100 \mathrm{gm}$ of brain at a hematocrit of 10 volumes \%. Oxygen delivery to the brain is shown in Figure $2 b$. While there was a significant relationship between the hematocrit and oxygen delivery, preservation of oxygen delivery occurred throughout the range of hematocrits studied $(\mathrm{y}=7.3+0.1 \mathrm{x}, r=0.39, p<0.01)$. The findings for cardiac blood flow (Fig. $3 a$ ) demonstrated a pattern similar to that seen for brain with a marked increase at lower hematocrits $\left(\mathrm{y}=47.6+\frac{78250}{\mathrm{x}^{2}}, r=0.79, p<0.001\right)$. However, oxygen delivery (Fig. $3 b$ ) remained stable throughout the hematocrit range with no suggestion of a decreasing delivery at the lowest range of hematocrits.

For the analysis of hepatic oxygenation a total of only 36 determinations on 12 lambs was used because the inferior vena cava catheter was not correctly located in the remaining studies. The entire data set was used for blood flow and oxygen delivery calculations. Total hepatic blood flow (Fig. 4a) showed a small decrease as hematocrit was increased while at lower hematocrits there was a fairly wide scatter of values ( $\mathrm{y}=268.7-0.04 \mathrm{x}^{2}, r=$ $-0.45, p<0.01)$. Since the changes in blood flow were rather limited as hematocrit decreased, oxygen delivery markedly decreased (Fig. $4 b$ ) to approximately $6 \mathrm{ml}$ of oxygen $/ \mathrm{min} / 100 \mathrm{~g}$ of liver at a hematocrit of 10 volumes $\%$. Oxygen delivery increased with increasing polycythemia. The overall relationship between hematocrit and oxygen delivery was curvilinear with a less step increase in blood flow at the higher hematocrits $(y=123.5-$ $\left.161\left(\frac{\operatorname{Lnx}}{\sqrt{\mathrm{x}}}\right), r=-0.80, p<0.001\right)$. Hepatic oxygen consumption (Fig. $5 a$ ) was maintained throughout the range of hematocrits. In order to maintain a stable oxygen consumption at a time when delivery of oxygen decreased, there was a steep increase in oxygen extraction as the hematocrit decreased (Fig. $5 b$ ). At the lowest hematocrit, $80 \%$ of the oxygen delivered was consumed
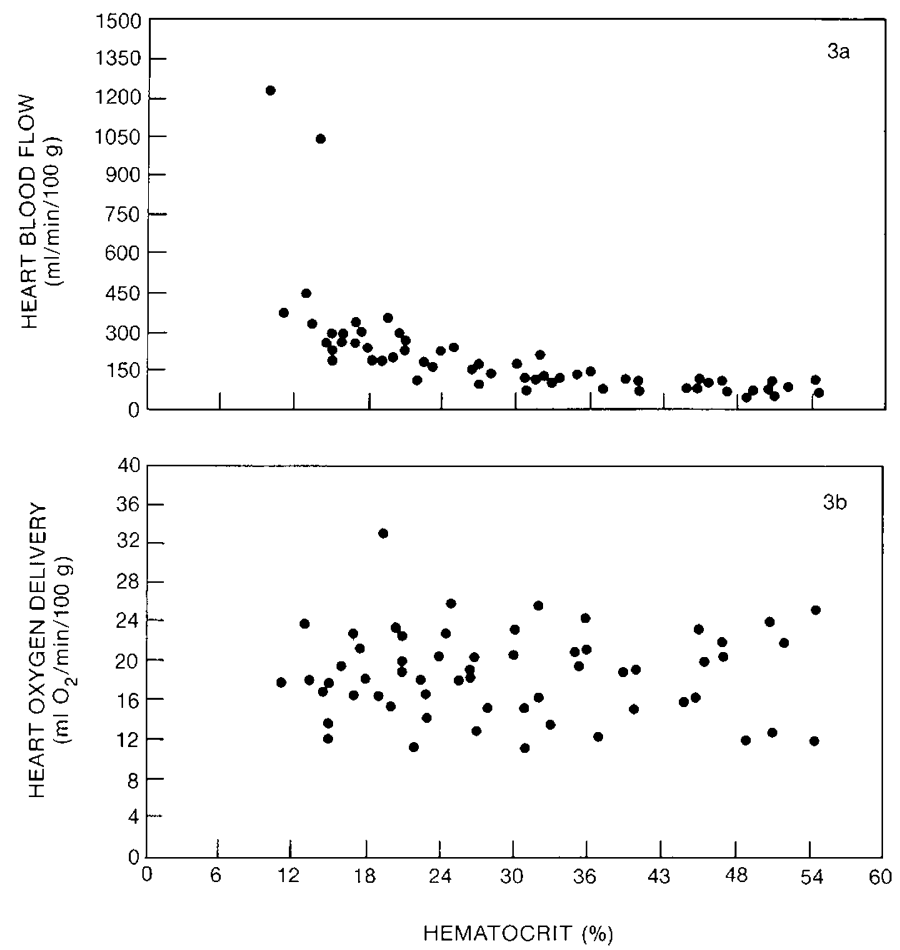

Fig. 3. $a$, the relationship between cardiac blood flow and changes in hematocrit; $n=59$ points from 15 lambs. $b$, the lack of a relationship between cardiac oxygen delivery and hematocrit; $n=59$ points from 15 lambs. 

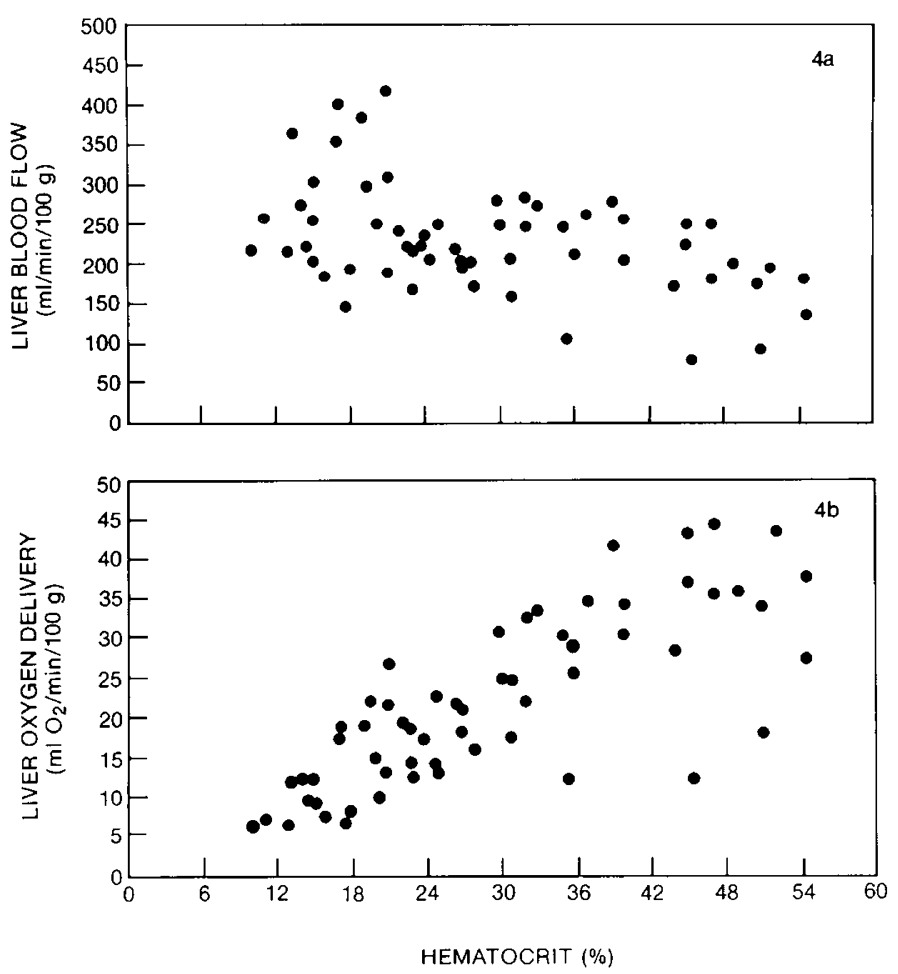

Fig. 4. $a$, the relationship between total hepatic blood flow and changes in hematocrit; $n=59$ points in 15 lambs. $b$, the relationship between total hepatic oxygen delivery and changes in hematocrit; $n=59$ points from 15 lambs.
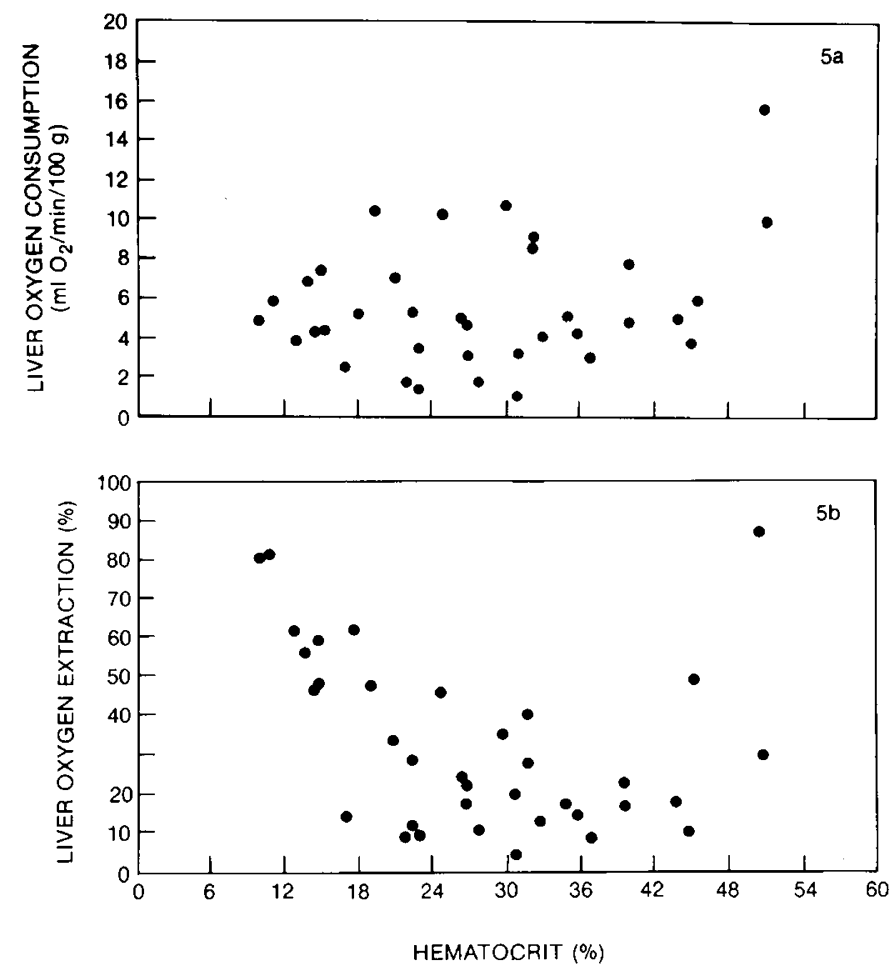

Fig. 5. $a$, the lack of relationship between hepatic oxygen consumption and hematocrit; $n=36$ points from 12 lambs. $b$, the relationship between hepatic oxygen extraction (oxygen consumption divided by oxygen delivery $\times 100$ ) and changes in hematocrit; $n=36$ points from 12 lambs.

$\left.\left(\mathrm{y}=18.2+\frac{6562.3}{\mathrm{x}^{2}}\right), r=0.66, p<0.001\right)$.

A linear relationship $(\mathrm{y}=29.8-0.31 \mathrm{x}, r=-0.67, p<0.001)$ existed for blood flow to the carcass (Fig. $6 a$ ) over the entire range of hematocrits. The increase of flow at the lower hematocrits was inadequate to preserve oxygen delivery $(\mathrm{y}=7.3-6.0$ $\left.\left(\frac{1+\operatorname{Lnx}}{\sqrt{\mathrm{x}}}\right), r=-0.76, p<0.001\right)$ at a stable level (Fig. 6b) resulting in deliveries as low as $1 \mathrm{ml}$ of oxygen $/ \mathrm{min} / 100 \mathrm{~g}$ of carcass at a hematocrit of 13 volumes \%. In those animals made polycythemic, oxygen delivery remained stable throughout the entire range of hematocrits.

Renal blood flow (Fig. $7 a$ ) remained unchanged (mean $=298$ $\pm 78 \mathrm{ml} / \mathrm{min} / 100 \mathrm{~g}$ ) regardless of the hematocrit. Thus, oxygen delivery (Fig. $7 b)$ is described by a linear relationship $(\mathrm{y}=2.8+$ $1.2 \mathrm{x}, r=0.82, p<0.001$ ) with deliveries as low as $10 \mathrm{ml}$ of oxygen $/ \mathrm{min} / 100 \mathrm{~g}$ of kidney at a hematocrit of 10 volumes $\%$.

Two other organs, the spleen and lung, showed a similar pattern of response as hematocrit was changed. Blood flow to both organs demonstrated a small increase at the lower hematocrits and a more marked decrease in flow at the higher hematocrits. In both cases, oxygen delivery was maintained until the hematocrit fell below approximately 18 volumes $\%$.

Concomitant with the changes in organ blood flow there were also small changes in the distribution of flow as a function of the total cardiac output. Both cerebral and cardiac blood flow accounted for a statistically significant increase in the percent of cardiac output directed to them as the hematocrit was decreased below 20 volumes \%. The average $( \pm \mathrm{SD})$ cerebral blood flow, as a percent of cardiac output, at a hematocrit $>20$ volumes $\%$ was $3.9 \pm 1.2 \%$ while it was $5.5 \pm 2.7 \%$ at a hematocrit $\leq 20$ volumes \%. Cardiac blood flow accounted for $8.6 \pm 4.6 \%$ of cardiac output at a hematocrit $\leq 20$ volumes $\%$ while it accounted for $4.7 \pm 1.2 \%$ of cardiac output at a hematocrit over 20 volumes $\%$. There were no other significant alterations in the distribution of cardiac output to the remainder of the organs during anemia or to any organs during polycythemia.

\section{DISCUSSION}

It is critical for the newborn to be able to assure an adequate oxygen delivery to a wide variety of organs during periods of
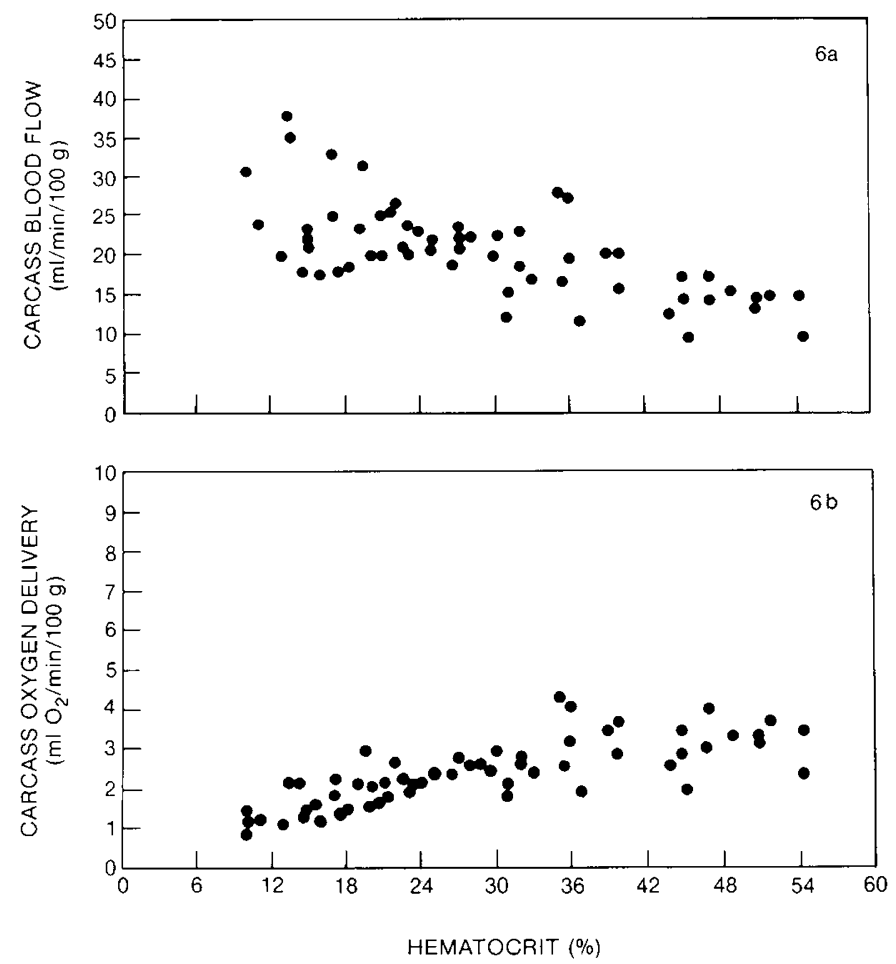

Fig. 6. $a$, the relationship between carcass blood flow and changes in hematocrit; $n=59$ points from 15 lambs. $b$, the relationship between carcass oxygen delivery and changes in hematocrit; $n=59$ points from 15 lambs. 

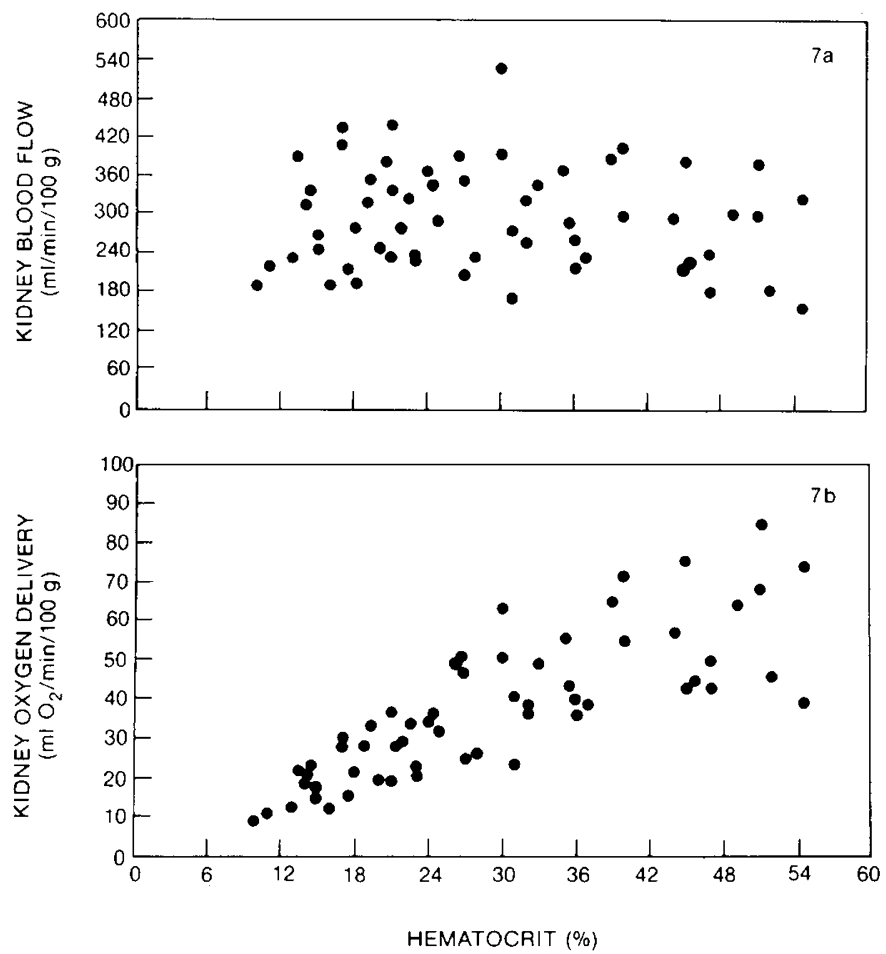

Fig. 7. $a$, the lack of relationship between renal blood flow and hematocrit; $n=59$ points from 15 lambs. $b$, the linear relationship between renal oxygen delivery and changes in hematocrit; $n=59$ points from 15 lambs.

anemia or polycythemia. A change in hematocrit, without accompanying hyper- or hypovolemia, directly influences oxygen availability by a change in the oxygen content of blood. At the extremes of hematocrit, viscosity may influence an organ's ability to meet its oxygen requirements because of either sludging or a maldistribution of red blood cells. One explanation for the maintenance of oxygen consumption during periods of altered oxygen availability is the metabolic theory of blood flow regulation (17). This theory states that cellular oxygen flux is the controlled variable rather than blood flow. A constant influx of oxygen intracellularly is maintained by precapillary sphincters which adjust the available capillary surface for oxygen diffusion and by terminal arterioles which affect local perfusion. Adjustments can be made in the capillary surface area, the intercapillary distance, or the $\mathrm{PO}_{2}$ gradient such that more oxygen is removed from the perfusing blood. It is also possible for total perfusion to the organ to increase. The dynamic relationship at the tissue level between the availability of oxygen and the demand for oxygen is thought to determine which adjustments will occur (18).

In the present series of experiments, 1- to 2-wk-old lambs were made either anemic or polycythemic by isovolemic exchange transfusions in order to examine the entire spectrum of cardiovascular adjustments. The limiting factor in extending the range of hematocrits studied was the inability of lambs to survive for an extended period of time with hematocrits less than 12 volumes $\%$ or greater than 60 volumes $\%$. When the hematocrit is decreased to between $10-15$ volumes $\%$, the total quantity of oxygen in arterial blood ( $\sim 5-6 \mathrm{ml}$ of oxygen/100 $\mathrm{ml})$ approaches a critical point below which tissue hypoxia occurs. Furthermore, at such low hematocrits, the experimental model is too unstable to study blood flow reliably by the microsphere technique. Similarly, at hematocrits greater than 60 volumes \%, there appears to be an interference with oxygenation. This may well represent the point at which viscosity markedly increases in the blood of lambs (19). Nevertheless, the present experiments include a wide range of hematocrits which have important clinical applicability.
The curvilinear relationship between cardiac output (and heart rate) and hematocrit reflects the total compensatory adjustments required to assure an adequate oxygen delivery to the various organs of the neonatal lamb. Two different forces are operating, especially at the extremes of hematocrit. Tissue-specific vasomotor tone and blood viscosity may act in concert or in opposition to each other. The overall changes in the newborn lamb are similar to those described in adult animals $(20,21)$ but differ from that described in the fetal lamb. Specifically, fetal cardiac output and heart rate do not increase, as they do in newborns and adults, when hematocrit is decreased to as low as 12 volumes $\%$ (1). While a number of other compensations at the tissue level are occurring at low hematocrits, it appears that fetal cardiac output is near maximal even at physiologic hematocrits. The finding of a decreasing whole body oxygen consumption as hematocrit is decreased is in keeping with our understanding of the relationship between the high metabolic needs of the newborn and its ability to meet these needs under extreme circumstances. Various experimental protocols have been employed to assess the interrelationship between neonatal age and size, hemoglobin type and concentration, and metabolic demand and their impact on whole body oxygen consumption (22). Because each of these factors is rapidly changing in the newborn, it is impossible to derive a single hematocrit or hemoglobin concentration at which oxygen consumption decreases. Furthermore, the diversity between individual animals accounts for the necessity to use an analysis of covariance to demonstrate a decreasing oxygen consumption. While the present data would not support a strong relationship between decreasing hematocrit and oxygen consumption, both previous experiments and the present data do indicate some inability of the newborn to maintain a stable oxygen consumption during a period of severe anemia.

The marked changes seen in both cerebral and cardiac blood flow with anemia confirm the importance of blood flow for the maintenance of oxygen consumption in these organs. While the delivery of oxygen to these organs was, for the most part, preserved, the scatter of individual responses suggests other uncontrolled variables in effect at low hematocrits. The clinical significance of increased cerebral and myocardial blood flow at low hematocrits (or during hypoxemia) cannot be overstated. Interventions that interfere with this compensation such as systemic vasodilators (23), may have unanticipated effects. The influence of polycythemia on cerebral blood flow was small in the present study but this probably represents the minimal number of animals studied at the highest hematocrits. The delivery of oxygen was well maintained and the overall findings are consistent with the work of Rosenkrantz et al. (25). The influence of an increased hematocrit on myocardial blood flow is clearer from the present data. The lowest blood flow measurements occurred in the lambs with the highest hematocrits. Oxygen delivery, paralleling the findings for brain, remained stable. Surjadhana et al. (7) showed unchanged myocardial blood flow in adult animals with even higher hematocrits but their experimental design differed greatly from the present studies. In the fetal lamb, both cerebral and myocardial blood flow increased in animals studied at comparably increased hematocrits (1) but these fetuses developed arterial hypoxemia at hematocrits above 40 volumes $\%$. Much as in the present experiments, cerebral and myocardial oxygen delivery remained stable during polycythemia.

The blood flow response of the carcass, an amalgum of tissues including skin, bone, and muscle, represents what might be predicted primarily on the basis of a change in viscosity occurring with the change in hematocrit (25). There was no change in the proportion of cardiac output directed to this group of tissues which, taken as a single organ, accounts for over $50 \%$ of cardiac output. Renal blood flow remained remarkably constant throughout the range of hematocrits studied. This is similar to the findings in the fetal lamb (1) with the exclusion of the changes seen during fetal hypoxemia. Experiments performed on adult rats suggest an increase in renal blood flow during anemia (3) 
but the experimental protocols differ greatly from the present study. The lack of a clear increase in blood flow in the present study is reflected in the linear relationship between the delivery of oxygen and hematocrit. As is the case for the carcass, blood flow is not tightly controlled in order to maintain a constant oxygen delivery. No attempt was made in this series of experiments to examine the redistribution of renal blood between the cortex and medulla. The importance of this has been discussed by Migdal et al. (27).

The findings for hepatic blood flow and oxygenation are in agreement with our overall understanding of the hepatic circulation. The liver of the newborn assures an adequate oxygen availability by varying extraction rather than relying on blood flow and oxygen delivery (27). In the lamb, portal blood flow accounts for $80-90 \%$ of total hepatic perfusion. Thus, changes in gastrointestinal perfusion due to either the effects of viscosity or circulatory adjustments directly influence portal blood flow. We have previously shown (27) that intestinal blood flow is constant when the hematocrit is varied over the present range of values. The decreased hepatic blood flow at the higher hematocrits most likely represents the effects of viscosity, but there may be some degree of vasoregulation of flow. The small contribution of arterial blood flow to total hepatic perfusion precludes a meaningful analysis of changes in the arterial blood flow with increasing hematocrit using the present methodology. Comparable data on human infants are not available. The ability of the liver to markedly increase oxygen extraction during periods of decreased oxygen availability has been shown in a number of experimental situations (27). The present data demonstrate that a similar mechanism operates during anemia with extractions as great as $80 \%$ occurring at the lowest hematocrits. We are unable to prove experimentally any interference with hepatic oxygenation within the range of hematocrits studied. While substrate delivery may well be affected at higher hematocrits (thus, contributing to disturbances in glucose and bilirubin metabolism), oxygen availability seem less likely to be the limiting factor. Although the methodology employed in the present study relies on the assumption of adequate mixing of blood in venous streams, the data are at least consistent with known hepatic physiology and have been verified using independent methods (28).

The integrated response of the newborn to changes in hematocrit functions to assure adequate tissue oxygenation. Two major patterns of adaptation can be seen. The brain and heart vary blood flow with substantial increases occurring during anemia-an adjustment that provides an adequate delivery of oxygen over a wide range of hematocrits. The influence of changes in viscosity may be relatively small. Admittedly, the elevated hematocrits obtained in the present experiment were not as high as is seen in the clinical care of the newborn, but they were nearly twice the normal hematocrit of newborn lambs and were in a range where hyperviscosity occurs experimentally (19). The vast majority of the remaining organs respond to a change in hematocrit by either varying oxygen extraction or oxygen consumption. Since the present methodology did not allow for measuring individual organ oxygen consumption other than the liver, no statement can be made as to whether the needs of each organ were met by the utilization of increasing oxygen extraction. The finding of a decreasing whole body oxygen consumption at the lower hematocrits would certainly suggest some effect on oxygen consumption in at least some of the organs. This degree of adjustment was adequate to prevent the development of systemic acidemia.

Acknowledgments. The authors thank Ms. Betty Steranka for her skilled technical support and Ms. Karen Brustle and Ms. Kimberly Klos for their invaluable aid in preparation of this manuscript.

\section{REFERENCES}

1. Fumia FD, Edelstone DI, Holzman IR 1984 Blood flow and oxygen delivery to fetal organs as functions of fetal hematocrit. Am J Obstet Gynecol 150:274-282

2. Rakusan K, Rajhathy J 1972 Distribution of cardiac output and organ blood content in anemic and polycythemic rats. Can J Physiol Pharmacol 50:703710

3. Ackermann U, Veress AT 1980 Regional blood flows and cardiac output distribution in rats during acute anemia or polycythemia. Can J Physiol Pharmacol 58:411-415

4. Replogle RL, Merrill EW 1970 Experimental polycythemia and hemodilution. Physiologic rheologic effects. J Thorac Cardiovasc Surg 60:582-588

5. Woodson RD, Auerbach S 1982 Effect of increased oxygen affinity and anemia on cardiac output and its distribution. J Appl Physiol 53:1299-1306

6. McGrath RL, Weil JV 1978 Adverse effects of normovolemic polycythemia and hypoxia on hemodynamics in the dog. Circ Res 43:793-798

7. Surjadhana A, Rouleau J, Boerboom L, Hoffman JIE 1978 Myocardial blood flow and its distribution in anesthetized polycythemic dogs. Circ Res 43:619631

8. Weisse AB, Calton FM, Kuida H, Hecht HH 1964 Hemodynamic effects of normovolemic polycythemia in dogs at rest and during exercise. Am J Physiol 207:1361-1366

9. Leake RD, Chan GM, Zakauddin S, Dodge ME, Fiser RH, Bier DM, OH W 1980 Glucose perturbation in experimental hyperviscosity. Pediatr Res 14:1320-1323

10. Olsen $C 1971$ An enzymatic fluorometric micromethod for the determination of acetoacetate, beta-hydroxybutyrate, pyruvate and lactate. Clin Chim Acta 33:293-300

11. Rosenberg AA, Jones MD, Koehler RC, Traystman RJ, Lister G 1983 Precautions for measuring blood flow during anemia with the microsphere technique. Am J Physiol 244(Heart Circ Physiol):H308-H31

12. Heymann MA, Payne BD, Hoffman JIE, Rudolph AM 1977 Blood flow measurements with radionuclide-labeled particles. Prog Cardiovasc Dis 20:55-79

13. Edelstone DI, Holzman IR 1981 Oxygen consumption by the gastrointestinal tract and liver in conscious newborn lambs. Am $J$ Physiol 240(Gastrointestinal Liver Physiol):G297-304

14. Dole WP, Jackson DL, Rosenblatt JI, Thompson WL 1982 Relative error and variability in blood flow measurements with radiolabeled microspheres. Am J Physiol 243(Heart Circ Physiol):H371-H378

15. Lautt WW 1976 Method for measuring hepatic uptake of oxygen or other blood-borne substances in situ. J Appl Physiol 40:269-274

16. Holzman I, Tabata B, Edelstone DI 1985 The effects of varying hematocrit on intestinal oxygen uptake in neonatal lambs. Am $J$ Physiol 248(Gastrointestinal Liver Physiol):G432-G436

17. Zar JH 1974 Biostatistical Analysis. Prentice Hall, Englewood Cliffs, NJ, pp 198-227

18. Granger HJ, Shepherd AP Jr 1973 Intrinsic microvascular control of tissue oxygen delivery. Microvasc Res 5:49-72

19. Granger HJ, Norris CP 1980 Intrinsic regulation of intestinal oxygenation in the anesthetized dog. Am J Physiol 238):Heart Circ Physiol):H836-H843

20. Riopel L, Fouron JC, Bard H 1983 A comparison of blood viscosity between the adult sheep and newborn lamb. The role of plasma and red blood cell type. Pediatr Res 17:452-455

21. Fan F, Chen RYZ, Schuessler GB, Chien S 1980 Effects of hematocrit variations on regional hemodynamics and oxygen transport in the dog. Am J Physiol 238:H545-H552

22. Van Ameringen MR, Fouron JC, Bard H, LeGuennec JC, Prosmanne J 198 Oxygenation in anemic newborn lambs with high or low oxygen affinity red cells. Pediatr Res 15:1500-1503

23. Lister G, Moreau G, Moss M, Talner NS 1984 Effects of alterations of oxygen transport on the neonate. Semin Perinatol 8:192-204

24. Mirro R, Milley JR, Holzman IR 1985 The effects of sodium nitroprusside on blood flow and oxygen delivery to the organs of the hypoxemic newborn lamb. Pediatr Res 19:15-18

25. Rosenkrantz TS, Stonestreet BS, Hansen NB, Nowicki P, Oh W 1984 Cerebral blood flow in the newborn lamb with polycythemia and hyperviscosity. $J$ Pediatr 104:276-280

26. Chapler CK, Cain SM 1981 Blood flow and $\mathrm{O}_{2}$ uptake in dog hindlimb with anemia, norepinephrine, and propranolol. J Appl Physiol 51:565-570

27. Migdal S, Alexander EA, Bruns FJ, Riley AL, Levinsky NG 1975 Effect of hemodilution on the distribution of renal blood flow. Circ Res 36;71-75

28. Holzman IR 1984 Fetal and neonatal hepatic perfusion and oxygenation. Semin Perinatol 8:234-244 